\title{
Multidisciplinary investigation of a multicountry outbreak of Salmonella Stanley infections associated with turkey meat in the European Union, August 2011 to January 2013
}

P Kinross $^{1,2,3}$, L van Alphen ${ }^{1,3,4}$, J Martinez Urtaza ${ }^{1}$, M Struelens ${ }^{1}$, J Takkinen ${ }^{1}$, D Coulombier ${ }^{1}$, P Mäkelä 5 , S Bertrand 6 , W

Mattheus ${ }^{6}$, D Schmid7, E Kanitz ${ }^{7}$, V Rücker ${ }^{8}$, K Krisztalovics 9 , J Pászti ${ }^{9}$, Z Szögyényi ${ }^{10}$, Z Lancz ${ }^{10}$, W Rabsch ${ }^{11}$, B Pfefferkorn ${ }^{12}$, P Hiller $^{13}$, K Mooijman ${ }^{14}$, C Gossner (Celine.Gossner@ecdc.europa.eu) ${ }^{1,15}$

1. European Centre for Disease Prevention and Control (ECDC), Stockholm, Sweden

2. European Programme for Intervention Epidemiology Training (EPIET), ECDC, Sweden

3. These authors contributed equally to this article.

4. European Programme for Public Health Microbiology Training (EUPHEM), ECDC, Sweden

5. European Food Safety Authority (EFSA), Parma, Italy

6. Wetenschappelijk Instituut Volksgezondheid/Institut scientifique de Santé-Publique, Brussels, Belgium

7. Österreichische Agentur für Gesundheit und Ernährungssicherheit (AGES), Vienna, Austria

8. Bundesministerium für Gesundheit (BMG), Bereich Verbrauchergesundheit, Vienna, Austria

9. Országos Epidemiológiai Központ (OEK), Budapest, Hungary

10. National Food Chain Safety Office, Ministry of Rural Development, Budapest, Hungary

11. National Reference Centre for Salmonella and other Bacterial Enteric Pathogens, Robert Koch-Institute (RKI), Wernigerode, Germany

12. Bundesamt für Verbraucherschutz und Lebensmittelsicherheit, Berlin, Germany

13. Bundesinstitut für Risikobewertung (BfR), Berlin, Germany

14. European Union Reference Laboratory for Salmonella, Bilthoven, the Netherlands

15. School of Public Health and Primary Care (CAPHRI), Maastricht University Medical Center (MUMC+), Maastricht, the Netherlands

Kinross P, van Alphen L, Martinez Urtaza J, Struelens M, Takkinen J, Coulombier D, Mäkelä P, Bertrand S, Mattheus W, Schmid D, Kanitz E, Rücker V, Krisztalovics K, Pászti J, Szögyényi Z, Lancz Z, Rabsch W, Pfefferkorn B, Hiller P, Mooijman K, Gossner C. Multidisciplinary investigation of a multicountry outbreak of Salmonella Stanley infections associated with turkey meat in the European Union, August 2011 to January 2013. Euro Surveill. 2014;19(19):pii=20801. Available online: http:// www.eurosurveillance.org/ViewArticle.aspx?Articleld=20801

Between August 2011 and January 2013, an outbreak of Salmonella enterica serovar Stanley (S. Stanley) infections affected 10 European Union (EU) countries, with a total of 710 cases recorded. Following an urgent inquiry in the Epidemic Intelligence Information System for food- and waterborne diseases (EPIS-FWD) on 29 June 2012, an international investigation was initiated including EU and national agencies for public health, veterinary health and food safety. Two of three local outbreak investigations undertaken by affected countries in 2012 identified turkey meat as a vehicle of infection. Furthermore, routine EU monitoring of animal sources showed that over $95 \%(n=298)$ of the 311 $S$. Stanley isolates reported from animal sampling in 2011 originated from the turkey food production chain. In 2004-10, none had this origin. Pulsed-field gel electrophoresis (PFGE) profile analysis of outbreak isolates and historical $S$. Stanley human isolates revealed that the outbreak isolates had a novel PFGE profile that emerged in Europe in 2011. An indistinguishable PFGE profile was identified in 346 of 464 human, food, feed, environmental and animal isolates from 16 EU countries: 102 of 112 non-human isolates tested were from the turkey production chain. On the basis of epidemiological and microbiological evidence, turkey meat was considered the primary source of human infection, following contamination early in the animal production chain.

\section{Introduction}

In Europe, between 2007 and 2011, Salmonella enterica serovar Stanley (S. Stanley) was relatively rarely reported in humans, with 2,647 $S$. Stanley cases reported to the European Surveillance System (TESSy) during the five-year period [1]. Reporting of all Salmonella cases is mandatory within the European Union (EU). Of the 2,044 cases with information on probable country of infection, $1,498(73 \%)$ were acquired outside the EU, of whom above $80 \%$ had recorded travelling to south-east Asia in the days before symptom onset; nine cases per month were autochthonous $[2,3]$.

In 2004-10, there were eight reports per month of isolation of $S$. Stanley from food, animals and feed by EU Member States [2,3]. In the past 10 years, only two reports of $S$. Stanley outbreaks in Europe have been published: in 2001, an international outbreak (involving Australia, Canada and the United Kingdom) due to the consumption of imported peanuts [4] and in 2007 , an outbreak in Sweden linked to alfalfa sprouts [5]. 
There is no indication that the clinical presentation of $S$. Stanley cases differs from that of other non-typhoidal Salmonella infections, especially in terms of severity [6].

On 29 June 2012, the Belgium National Reference Centre for Salmonella reported the detection of 20 autochtonous cases of $S$. Stanley infection in the first half of 2012, compared with 3, 6 and 19 cases detected in 2009, 2010 and 2011, respectively. S. Stanley isolates from the 20 cases in 2012 were all nalidixic acid resistant and 18 of them had an indistinguishable $\mathrm{Xbal}$ pulsed-field gel electrophoresis (PFGE) pattern. On 3 July 2012, Germany reported a twofold increase in the number of cases of $S$. Stanley infection in the first half of 2012 compared with the number in same period the previous years, with 34 domestic and nine travelrelated cases. On 11 July 2012, Hungary also notified an increase in the number of cases of $S$. Stanley infection, with 63 cases in 2012 compared with the 2 to 10 cases expected annually. On 17 July 2012, the Belgium National Reference Centre for Salmonella confirmed the PFGE pattern of isolates from the Hungarian cases was indistinguishable from the Belgian pattern. On 6 August 2012, Austria reported an increase in the number of cases of $S$. Stanley infection $(n=37)$ with a nalidixic acid mono-resistant profile observed between April and July, compared with eight cases in the first quarter that year.

As more information from the food sector became available, the European Commission asked the European Centre for Disease Prevention and Control (ECDC) and the European Food Safety Authority (EFSA) for technical assistance in the evaluation of information collected during the outbreak investigation. Rapid outbreak assessments were initiated by ECDC in collaboration with EFSA, the European Reference Laboratory for Salmonella (EURL-Salmonella) and affected EU/ European Economic Area (EEA) countries to identify outbreak-related cases, describe the outbreak size and progression and provide evidence supporting the implementation of control measures. ECDC provided the first assessment of this information on 27 July 2012 [2], an update on 29 August and a further update jointly with EFSA on 21 September 2012 [3]. To our knowledge, this is the first large multicountry outbreak of $S$. Stanley infection, investigated through both epidemiological and microbiological investigation coordinated at the EU level.

\section{Methods}

Epidemiological and microbiological information for risk analysis was shared through the Epidemic Intelligence Information System for food- and waterborne diseases (EPIS-FWD) [7].

\section{European Union outbreak case definition}

A probable case was defined as a person with $S$. Stanley infection with an onset of symptoms after August 2011, and no travel history outside the EU in the seven days before the symptom onset, to focus the investigation on likely sources of infection within the EU. The definition's date restriction was chosen as the increased incidence in Hungary was observed from this time.

A confirmed case was a probable case with isolates showing an Xbal-PFGE pattern indistinguishable from the outbreak strain first detected in Belgium. Cases from whom isolates were tested by Xbal -PFGE and results patterns were different from the outbreak strain were excluded.

The case definition did not include antimicrobial sensitivity information. A 'case' refers to probable and confirmed cases, unless otherwise specified. A country reporting at least one confirmed case was considered affected.

From 1 October 2012, a monitoring phase was initiated: EU/EEA countries were asked to provide ECDC with their aggregate monthly number of non-travel-associated cases of S. Stanley infection. ECDC removed its recommendation on PFGE confirmation, which was costly and time consuming, to monitor the overall trend.

\section{Epidemiological investigations}

Data on cases were collected by national public health institutes. Baseline incidence was established by reviewing surveillance reports of human $S$. Stanley infection since 2007 (ECDC) and reports of S. Stanley infection in animals, food and feed since 2004 (EFSA). Population data were obtained from the 2010 Eurostat population dataset [8] and the incidence ranges per million population were determined using the geometrical interval classification method (ArcGIS v.10.2).

Investigators in Austria and Hungary created hypothesis-generating questionnaires, which served as a basis for the development of a standard EU questionnaire for interview of retrospective and prospective cases. The questionnaire focused on selected exposures in the seven days before symptom onset, and was shared with countries on 4 September 2011.

\section{Microbiological investigations}

For the microbiological investigations, the outbreak strain was defined as the first $S$. Stanley strain detected in Belgium in 2012. Outbreak isolates were isolates with an indistinguishable Xbal-PFGE pattern to the outbreak strain; no single band differences were accepted.

ECDC, EFSA and EURL-Salmonella jointly prepared a laboratory testing protocol for human, food and animal isolates, requesting PFGE analyses of selected $S$. Stanley isolates using the PulseNet protocol and $X b a l$ [9]. The clonality of the Xbal-PFGE outbreak strain was further analysed using a selection of human, animal, food and environmental isolates from Austria, Belgium and Hungary through use of a second restriction enzyme, Bnll. EU/EEA public health institutes were 
Confirmed and probable cases of Salmonella Stanley infection in humans by month of report in affected European Union Member States, August 2011-January 2013 ( $n=710)^{a}$

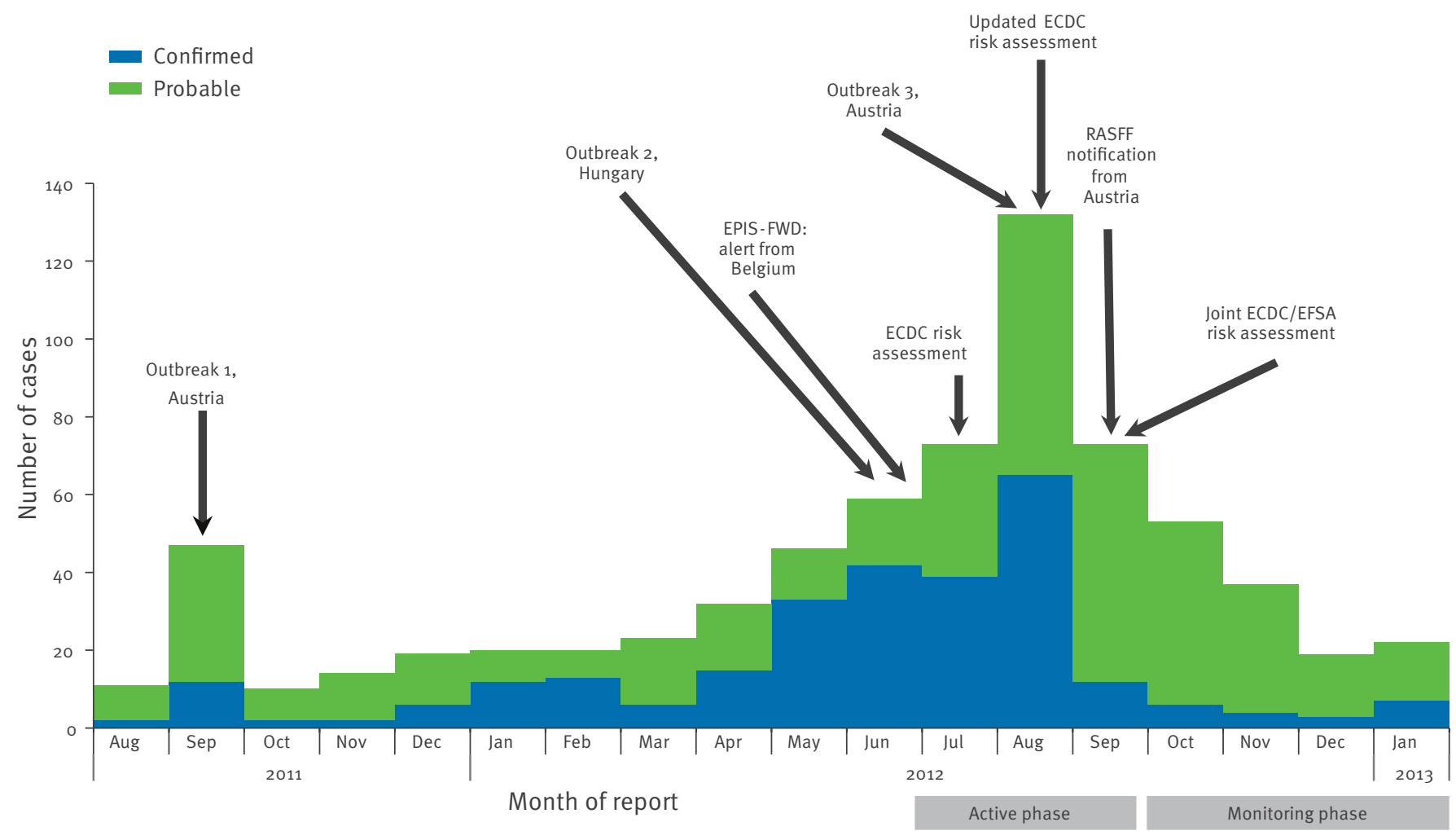

ECDC: European Centre for Disease Prevention and Control; EFSA: European Food Safety Authority; EPIS-FWD: Epidemic Intelligence Information System for food- and waterborne diseases; RASFF: Rapid Alert System for Food and Feed.

a Of the 710 isolates reported, 281 were confirmed to be the outbreak strain.

requested to share with ECDC PFGE typing results of isolates from patients meeting the EU outbreak case definition; animal health and food safety authorities were requested to share with EURL-Salmonella the PFGE typing results of $S$. Stanley-positive isolates with the outbreak strain from animal, food and environment sampling.

EU/EEA veterinary and food reference laboratories were requested to share PFGE typing results from isolates from food, feed, environment and animals since 2007 and to perform PFGE typing on stored S. Stanley isolates from January 2011 onwards, and on new isolations.

Quality assessment of the shared PFGE gel pictures was performed according to the PulseNet international protocol PNQ01 [10]. Cluster analysis was performed using Bionumerics V6.6 (Applied Maths, Sint-MartensLaten, Belgium) with tolerance and optimisation set at $1.5 \%$. Analysis of the pattern variation within the clusters was reassessed setting the optimisation and tolerance thresholds at $1 \%$. A cluster was defined as a group of isolates of $S$. Stanley with indistinguishable Xbal-PFGE patterns.

The PulseNet Europe PFGE database hosted at ECDC was used to assess the genetic diversity of historical European S. Stanley isolates and to compare outbreak isolates' patterns with those of the 21,748 isolates of Salmonella spp. imaged between 1994 and 2008. In addition, ECDC consulted the EU Member States to determine whether they had identified the outbreak strain between 2008 and 2011. The Hunter-Gaston index was used to calculate the discriminatory power of the Xbal-PFGE typing [11].

International food safety notifications inside and outside the EU

ECDC liaised with the Rapid Alert System for Food and Feed (RASFF) of the European Commission to facilitate identification of internationally distributed products contaminated with S. Stanley. The International Food Safety Authorities Network (INFOSAN) issued an alert on 20 July 2012 to identify cases outside the EU/EEA. 
Distribution of cases of non-travel-related Salmonella Stanley infections (probable and confirmed cases) by European Union Member State, August 2011-January 2013 (n=710)

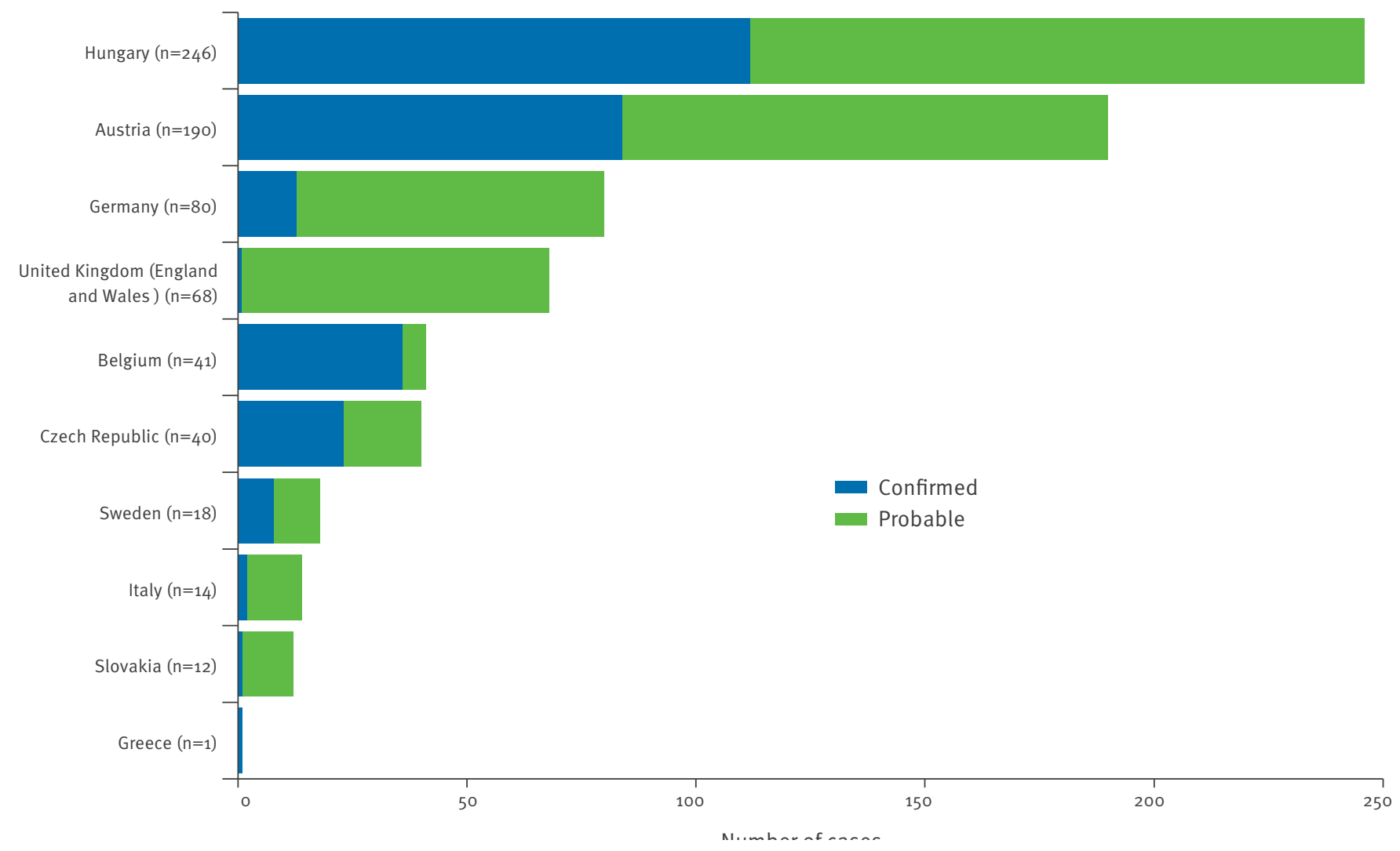

\section{Results}

\section{National outbreaks}

Austria investigated two local outbreaks. The first occurred in September 2011, before the multicountry alert [3] (Figure 1). A descriptive epidemiological study identified that all 32 cases (of whom five were confirmed) ate at a turkey kebab stand. No turkey meat remained for testing, but a sauce sample and dishcloth from the stand tested positive for S. Stanley. Both Xbal- and Bnll-PFGE analyses of the human, food and environmental isolates from this cluster were indistinguishable from that of the Belgian outbreak strain. The second outbreak occurred in August 2012 with 62 cases (of whom 54 were confirmed) following a local community event in Upper Austria [3]. Descriptive and analytical epidemiological investigations by the national Agency for Health and Food Safety (Agentur für Gesundheit und Ernährungssicherheit, AGES), assisting the local public health authorities, identified an association between the disease and consumption of a potato salad prepared by a person subsequently identified to have had an asymptomatic infection with the S. Stanley outbreak strain [3].

In Hungary, health authorities investigated an outbreak that occurred in June to July 2012 in a summer camp [3]. Its two confirmed cases both reported eating meatballs containing turkey meat. Leftover meatballs were not available for testing, but frozen turkey meat from the batch used to prepare the meatballs was positive for $S$. Stanley with the outbreak PFGE profile. Environmental isolates taken in August 2012 at the factory that processed this turkey meat also had a PFGE pattern indistinguishable from that of the outbreak strain. Isolates from the farm and slaughterhouse that supplied this contaminated meat tested positive for $S$. Stanley repeatedly during routine investigations in 2012, although no PFGE results were available.

\section{European Union investigation}

\section{Descriptive epidemiology}

Between 1 August 2011 and 31 January 2013, 710 human cases of S. Stanley infection were reported in $10 \mathrm{EU}$ Member States: Austria, Belgium, Czech Republic, Germany, Greece, Hungary, Italy, Slovakia, Sweden and the United Kingdom. Of these, 281 (40\%) were confirmed cases (Figures 1 and 2). PFGE testing was not performed on the remaining 429 probable cases.

The median age, for the 493 cases with available information, was 16 years (range: 0-89). Of the 497 cases with available information on sex, 259 ( $52 \%$ ) were male.

A total of 20 EU/EEA countries reported no unusual increase in the number of $S$. Stanley infections or no 


\section{FIGURE 3}

Incidence rates of confirmed and probable cases of Salmonella Stanley infection by European Union Member State region, 1 August 2011-22 October 2012a $(\mathrm{n}=498)^{\mathrm{b}}$
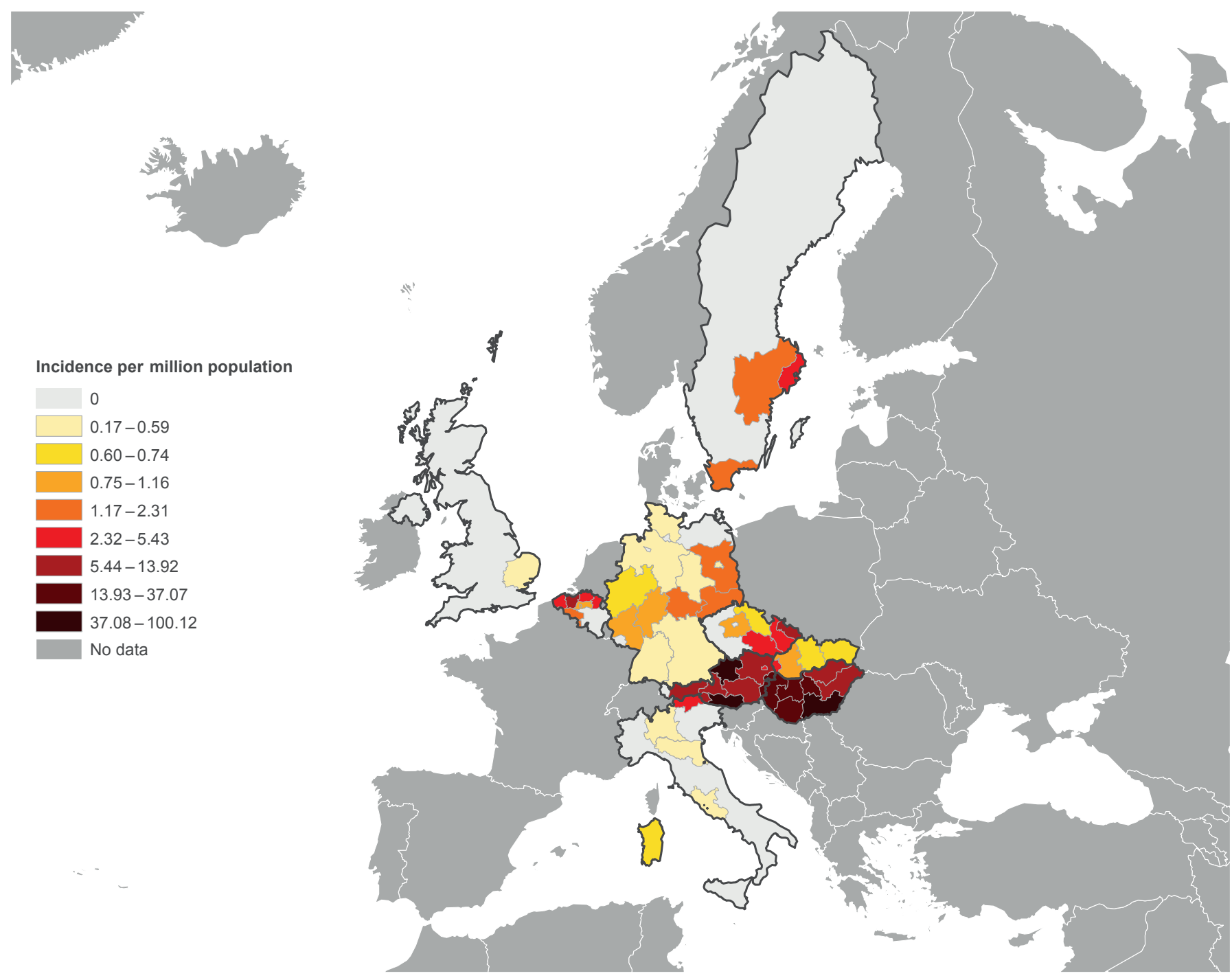

Incidence per million population

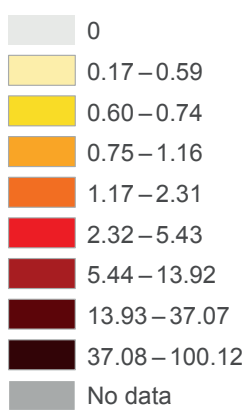

NUTS: nomenclature of territorial units for statistics.

a The map was generated once the outbreak investigation had moved to its monitoring phase.

b Cases for whom geographical information was available.

Population data were obtained from the 2010 Eurostat population dataset [9] and the incidence ranges per million population were determined using the geometrical interval classification method (ArcGIS v.10.2). The incidence rate in Austria, Belgium, Czech Republic, Hungary and Slovakia are represented at NUTS2 level; in Germany and the United Kingdom, at NUTS1 level.

cases associated with the outbreak. No cases were identified as a result of the INFOSAN alert [3].

Geographical clusters were observed in three countries: Belgium's cases were reported from the northern, Flemish part of the country; Sweden's cases clustered in the southern and south-eastern population centres; Austria's cases clustered in Upper Austria and Carinthia (Figure 3), partially due to two large outbreaks.

The monthly incidence at the EU level increased incrementally from February $(n=20)$ until August $2012(n=132)$, decreasing each month thereafter until December $2012(n=19)$.

\section{European Union standard questionnaires}

By 29 October 2012, ECDC had received 43 questionnaires from five countries: Belgium $(n=1)$, Czech Republic $(n=24)$, Greece $(n=1)$, Hungary $(n=11)$ and Slovakia $(n=6)$. Three questionnaires were excluded from the analysis due to incompleteness.

Meat was eaten by 39/40 respondents. Products explicitly labelled as turkey (e.g. roast turkey and turkey ham) 
were reported to have been eaten by $10 / 40$ overall. Two of these 10 cases ate barbequed 'back-yard' turkey.

\section{Control measures}

The European Commission's arranged ad hoc teleconferences to ensure communication between the competent authorities and trace-back/trace-forward investigations to more accurately determine the source of the outbreaks. Control measures were coordinated at the national level and communicated between countries, e.g. in a RASFF notification from Austria [12].

\section{Microbiological investigation of human, food and veterinary samples}

Of the 21,748 entries in the PulseNet Europe PFGE surveillance database between 1994 and 2008, 91 (0.4\%) were S. Stanley. A total of 72 different PFGE types were identified; none matched the 2011-12 outbreak PFGE profile (Figure 4). Additional comparisons with national PFGE databases from EU Member States confirmed that the outbreak profile had not been identified among isolates of $S$. Stanley from humans in the EU before August 2011.

In 2011, $311 \mathrm{~S}$. Stanley serovar isolations from routine monitoring of food and animals were reported to EFSA by EU Member States, Norway and Switzerland, of which $96 \%(n=298)$ were from turkey fattening flocks, turkey breeding flocks and turkey meat [3]. By comparison, between 2004 and 2010, S. Stanley was isolated on 55 occasions but not from turkeys or turkey meat [3].

S. Stanley was first identified in turkeys in January 2011 in Hungary, in breeding flocks. The animals had been imported as day-old chicks from a German hatchery, having tested negative for Salmonella spp. on arrival. Later that year, $S$. Stanley also appeared in turkey fattening flocks in Hungary (data not shown); however, no PFGE results were available for these isolates.

Austria's turkey hatchery received regular consignments of hatching eggs from a turkey parent flock in Hungary. Animal samples (boot swabs) from that parent flock were sent to the Austrian hatchery as part of its self-monitoring: they tested positive for nalidixic acid mono-resistant $S$. Stanley on several occasions from June 2011 onwards. Samples from the Austrian hatchery, taken in March 2012, also tested positive for the outbreak strain. In 2012, the Austrian hatchery distributed day-old chicks to fattening farms in Austria and 10 other countries, some of which reported confirmed human cases (Czech Republic and Hungary) and some that did not report any human cases (Croatia, Poland, Serbia and Slovenia). Subsequent to the detection of S. Stanley with the outbreak PFGE profile in a 'turkey stick' produced in Austria, the Austrian food authorities issued a RASFF notification on 10 September 2012 [12].
In 2012 in Hungary, 24 turkey holdings were found to be infected with $S$. Stanley (no PFGE results were available). Hungary isolated S. Stanley from 13 food samples from January to September 2012; all but one were from turkey meat; one sample was from broiler chicken meat (no PFGE results were available).

During the investigation, ECDC received PFGE profiles of $488 \mathrm{~S}$. Stanley isolates from human and non-human samples from 15 EU/EEA countries (Austria, Belgium, Czech Republic, Germany, Denmark, Greece, Finland, France, Hungary, Italy, Norway, Poland, Slovenia, Slovak Republic and the United Kingdom). A total of 464 PFGE profiles were included in the analysis, as 24 profiles were excluded for quality reasons. Bnll-PFGE profiling of a selection of human, animal, food and environmental isolates from three countries (Austria, Belgium and Hungary) confirmed the clonality of the Xbal-PFGE outbreak strain. The Xbal-PFGE outbreak profile was identified in 346 of the 464 profiles analysed.

For the isolates from human cases, ECDC received PFGE profiles of 234 isolates indistinguishable from the outbreak profile, from 281 reported confirmed cases. These 234 isolates with the outbreak profile were received from eight EU countries and showed that the first isolate from a human case was from Austria, from July 2011.

A total of 102 of 112 (91\%) isolates from animals, food, feed and environment were related to the turkey industry (Table). Of these 102 isolates, 20 were from turkey and turkey fattening flocks, 50 were from turkey meat or turkey-containing products originating from eight EU countries, one was from feed (consisting of turkey by-products) for fur animals and 31 were from environmental samples. The seven non-turkey-containing food products containing isolates with the outbreak profile included poultry and beef. Turkey hatcheries and turkey farms were the origin of 31 of the 33 indistinguishable environmental isolates.

\section{Discussion}

This is the first reported multicountry food-borne outbreak of S. Stanley infection in the EU. More than a third of EU countries were affected between 2011 and 2012. Multisectoral investigation of the incidence and distribution of the outbreak resulted in strong evidence pointing towards the turkey production chain and confirming the emergence of a new microbial clone within the EU. The PFGE typing with a second enzyme supported this conclusion. The strong microbiological evidence for turkey being the main infection source was supported by food and animal investigations, most particularly the temporal correlation between the emergence of $S$. Stanley in the turkey production chain before the outbreak in humans and identification of the outbreak strain in a batch of turkey meat consumed by two cases in Hungary. 


\section{FIGURE 4}

Dendrogram showing the similarity relationships of the 2011-12 European Union Salmonella Stanley outbreak strain among the different XbaI-PFGE types of S. Stanley isolates in the PulseNet Europe surveillance database (1994-2008)

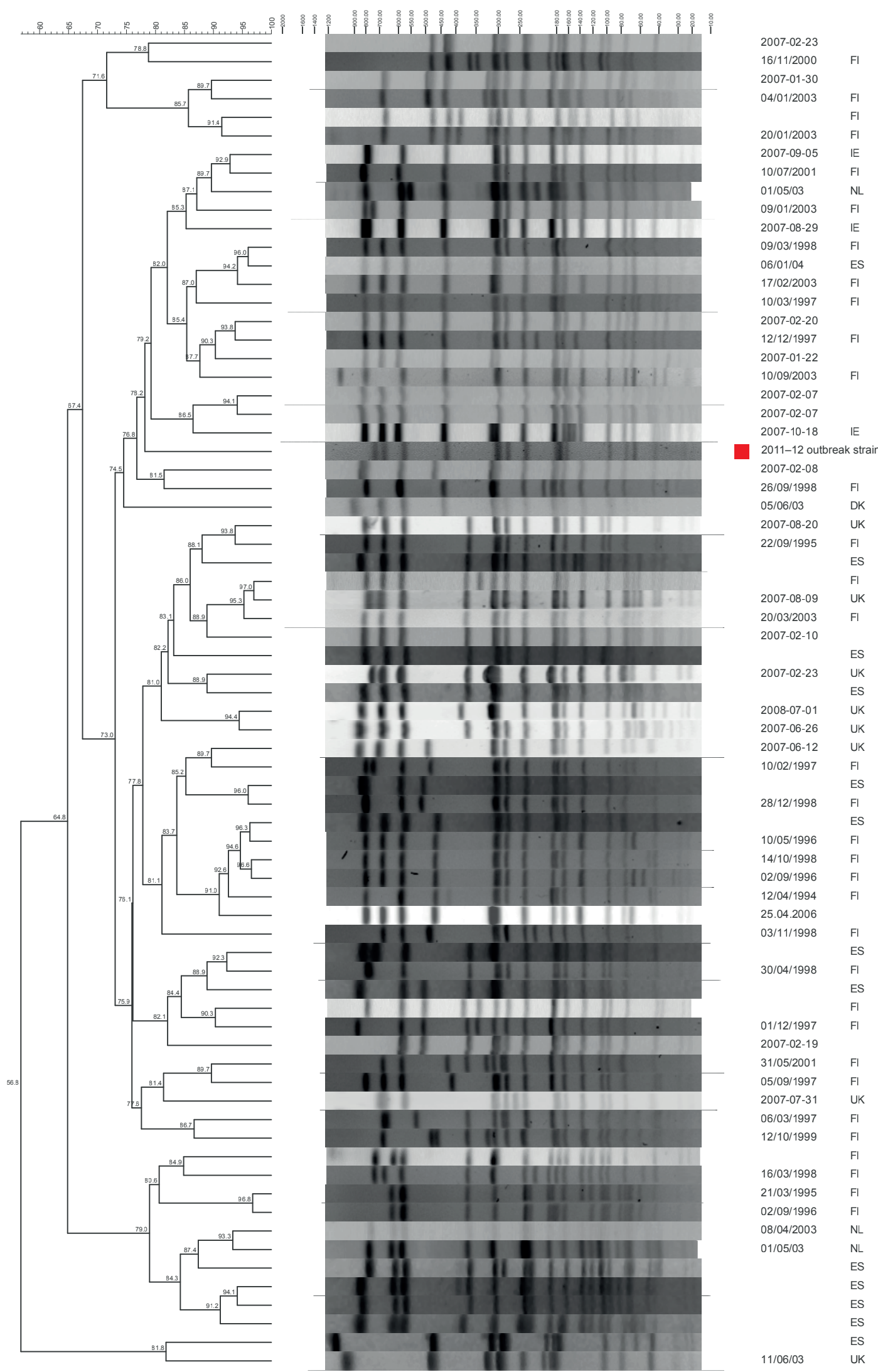

DK: Denmark; ES: Spain; FI: Finland; IE: Ireland; NL: the Netherlands; PFGE: pulsed-field gel electrophoresis; UK: United Kingdom. The Xbal-PFGE pattern of the 2011-12 European Union outbreak strain is marked with a red box.

The dendrogram was created with Bionumerics, with tolerance and optimisation set at $1.5 \%$. Analysis of the pattern variation within the clusters was reassessed setting the optimisation and tolerance thresholds at $1 \%$. 


\section{TABLE}

Source of isolation of Salmonella Stanley isolates with an XbaI-PFGE profile indistinguishable from that of the European Union 2011-2012 outbreak strain $(n=346$, aggregated data)

\begin{tabular}{|l|c|}
\hline Source of isolation & Number of Isolates \\
\hline Human & $\mathbf{2 3 4}$ \\
\hline Animal (boot swabs) & $\mathbf{2 1}$ \\
\hline Turkey (undefined flock type) & 12 \\
\hline Turkey fattening flock & 8 \\
\hline Unknown & 1 \\
\hline Food & $\mathbf{5 7}$ \\
\hline Turkey & 48 \\
\hline Turkey and beef & 2 \\
\hline Chicken & 2 \\
\hline Poultry & 1 \\
\hline Other meat & 4 \\
\hline Feed & $\mathbf{1}$ \\
\hline Turkey-containing fur-animal feed & 1 \\
\hline Environment & $\mathbf{3 3}$ \\
\hline Turkey hatchery/farm (floor) & 18 \\
\hline Turkey hatchery (breeding machine ) & 9 \\
\hline Turkey hatchery/farm (undefined) & 4 \\
\hline Other (dishcloth and refrigerator) & 2 \\
\hline Total & $\mathbf{3 4 6}$ \\
\hline
\end{tabular}

PFGE: pulsed-field gel electrophoresis.

Challenges in investigating a potentially widely distributed food source

This outbreak highlights the challenges in detecting and investigating food-borne events when contamination occurred early in the animal production chain, resulting in multiple vehicles of infection, contaminated over a long time period. Breaches in correct food handling resulted in sporadic cases and limited pointsource community outbreaks in several countries.

Due to early contamination of the turkey production chain, subsequent cross-contamination of other foodstuffs may have occurred. Therefore, positive findings in other food items (e.g. broiler meat and beef) are expected and do not contradict the main conclusion of a contaminated turkey meat production chain being the primary source of infection.

Standard questionnaires for affected countries did not allow the identification of a specific food item as a common exposure for cases. The questionnaires were completed by $4 \%(11 / 246)$ of cases in Hungary and were not used in Austria, two countries with $61 \%$ $(n=436)$ of all 710 cases; therefore, their representativeness was low. The development of the questionnaires was complicated by the sheer variety of meat choices, including national food specialties, within and between affected countries. Because of typing and reporting delays, many cases were interviewed long after their illness, increasing recall bias. Additionally, previous experience from a Salmonella outbreak in Germany suggested that assessment of turkey meat consumption using food consumption surveys is difficult, especially when the meat was in a composite food or labelled as 'poultry' (C Frank, personal communication, August 2012). These factors make it unlikely that a traditional case-control study at EU level would have provided strong epidemiological evidence. In such outbreaks, carefully performed retrospective analytical epidemiological studies on point-source sub-outbreaks would be more efficient in gathering epidemiological evidence. Detailed investigation, including analysis of recipes, shopping bills or loyalty card records may be effective additional tools if cases are identified and interviewed in a timely manner $[6,13,14]$.

The distribution of the cases in the Flemish region of Belgium was surprising. Most likely this reflects different eating habits or food distribution channels between Flemish- and French-speaking Belgium. This epidemiological characteristic could not be further investigated as it would have required intense trace-back, which was not possible at the time.

The added value of molecular typing for outbreak investigation has been discussed previously $[15,16]$. The standard PulseNet PFGE method is still the gold standard molecular typing method for Salmonella isolates. In spite of PFGE being laborious, taking two to three days, and the quality being dependent on equipment and technicians' skills, the PFGE testing was not a limiting factor for implementation of control measures. However, the lack of an integrated PFGE typing database for human and non-human Salmonella isolates required time-consuming coordination efforts at EU level. Therefore, further work is needed to allow rapid comparison of PFGE patterns across laboratories.

Antibiotic resistance data provided supportive evidence during the investigation. The resistance profile was not included in the case definition due to variations in national testing panels and methods, as well as different interpretive standards for testing human and animal isolates, which precluded comparability.

This outbreak demonstrates the complexity of defining triggers for implementation of control measures. How much evidence is needed to incriminate vehicles/ sources and launch appropriate control measures that could have positive protective public health effects but also financial consequences? At the European level, the role of ECDC and EFSA as risk assessment agencies is to provide all available evidence and critical analysis for risk managers at national and EU level so that appropriate control measures can be implemented. Feedback from risk managers on the implemented control measures supports the risk assessors in their continuous assessment of the event. Indeed, coordination of trace-back and trace-forward activities during large and complex multicountry outbreaks is crucial. This need was also underlined during a simulation exercise 
in May 2013 attended by representatives from the public health and food safety sector from 29 EU/EEA countries, Croatia, Switzerland and Turkey, EU agencies, Health Security Committee Communicators' Network communication specialists, the European Commission's Directorate-General for Health and Consumers (DG SANCO) and the World Health Organization Regional Office for Europe [17].

The 2003 regulation of the European Parliament and Council and its implementing provisions requires countries to monitor Salmonella serovars of public health relevance in breeding hens, laying hens, broilers and turkeys in the EU [18]. Results must be known before slaughter to permit appropriate measures that reduce consumers' exposure. Although EU targets for the reduction of Salmonella in turkey flocks are set up for S. Enteritidis and S. Typhimurium only [19], control measures such as biosecurity measures at farms and hygiene at slaughter are common to all serovars [19]. Therefore, control of Salmonella contamination in turkey flocks should result in the control of $S$. Stanley. In 2013, the number of human cases reported in the EU decreased compared with the outbreak's peak in 2012, but was still higher than that observed in 2009 and 2010 [20] More recently, two outbreaks of infection with the $S$. Stanley outbreak strain were reported by Germany (December 2013) and Austria (April 2014): both were due to consumption of contaminated turkey meat [20]. This may indicate that $S$. Stanley is still circulating in the turkey production chain in some EU Member States in 2014.

\section{Future directions}

For this outbreak, a joint ad hoc molecular typing database for comparison of human, animal, food and environment isolates was established at EU level. ECDC has upgraded TESSy and EPIS-FWD with a capacity to collect and analyse molecular typing and epidemiological data to facilitate the rapid detection of emerging clones and dispersed food-borne outbreaks in humans. At present, the pilot project includes reporting of PFGE for Salmonella spp., Shiga toxin-producing Escherichia coli and Listeria monocytogenes, as well as multiple-locus variable-number of tandem repeats analysis (MLVA) data for S. Typhimurium. EFSA, in collaboration with relevant European reference laboratories, is establishing similar molecular typing data collection for isolates from food and animal sources. This outbreak of S. Stanley infection demonstrated the importance of agreeing on the use of comparable molecular typing methods in both sectors.

A new version of EPIS-FWD was launched in July 2013. It links to TESSy and so facilitates assessment of clusters detected though molecular surveillance of human isolates. The new platform also allows food and veterinary experts to be invited to join designated discussions, to promote the intersectoral sharing of operational information [7].
Following this outbreak, ECDC, EFSA and the European Commission have been jointly developing procedures to ensure coordinated investigation and cross-sector data exchange. ECDC's Toolkit for investigation and response to food and waterborne disease outbreaks with an EU dimension provides material for public health investigators that also aims to aid coordination of such outbreak investigations in Europe [21]. The outbreak investigation reported here highlights the importance of timely submission of molecular typing data. Routine molecular typing and the prospective analysis of these data on a European level can facilitate early outbreak detection, more efficient outbreak investigation and influence intervention decisions. The European Commission has also initiated extensive training within the 'Better training for safer food' programme [22], aiming at training multidisciplinary teams to investigate food-borne outbreaks.

\section{Conclusions}

The PFGE pattern of the outbreak strain was new and emerged in 2011 in the EU. As the outbreak was noted among persons without travel history outside the EU, exposure to contaminated vehicles presumably took place in the EU. The temporal distribution of cases indicated gradual spread and transmission originating from persistent common sources. The broad geographical distribution of cases and non-human isolates suggests contamination of widely distributed products in several EU countries.

Comparison of PFGE profiles from human, veterinary and food isolates pointed towards a common source: the turkey production chain. The emergence of $S$. Stanley isolates in animals and food preceded the large increase in the number of human cases by less than a year and emergence took place mostly within turkey production. Identification of the outbreak strain in turkey meat at farm, factory and fork level in a number of countries confirms that the contamination occurred early in the animal production chain.

This outbreak investigation was complex, highlighting the difficulties in performing coordinated multicountry investigations from farm to fork. Early collaboration across public health, veterinary and food sectors in a One Health approach will help the EU's reactivity to future multicountry outbreaks, for timely implementation of control measures. 


\section{Acknowledgments}

We would like to acknowledge all national public health, food safety and veterinary institutes and laboratories in the affected Member States for their active participation in the international investigations; Rita Prager from the National Reference Centre for Salmonella and other Bacterial Enteric Pathogens in Germany for performing the PFGE typing and Christina Frank from the Robert Koch Institute for providing epidemiological data for Germany; ECDC surveillance team for providing background data from TESSy; ECDC GIS Team for providing the map; EPIET fellows in Austria, Belgium and Hungary for developing and piloting the EU trawling questionnaire.

\section{Conflict of interest}

None declared.

\section{Authors' contributions}

All authors have participated to the multicountry investigations and provided either epidemiological or microbiological or other food related information contributing to the response to the event. All authors have reviewed and provided substantial comments to the article.

Pete Kinross, Lieke van Alphen, Jaime Martinez Urtaza, Marc Struelens, Johanna Takkinen, Denis Coulombier and Céline Gossner (leader) were part of the ECDC outbreak response team which coordinated the investigations at the EU level.

Pia Mäkelä provided data collected by EFSA and its analysis. She also supported the collection of PFGE from food, animal and environmental samples.

Sophie Bertrand and Wesley Mattheus provided information for Belgium and posted the initial alert in EPIS-FWD; Daniela Schmid, Elisabeth Kanitz and Verena Rücker provided information for Austria; Katalin Krisztalovics, Judit Pászti, Zsuzsanna Szögyényi and Zsuzsanna Lancz provided information for Hungary; Wolfgang Rabsch, Beatrice Pfefferkorn and Petra Hiller provided information for Germany.

Kirsten Mooijman supported the collection of PFGE from food, animal and environmental samples.

\section{References}

1. European Centre for Disease Prevention and Control (ECDC). The European Surveillance System (TESSy). Stockholm: ECDC. [Accessed 15 May 2013]. Available from: http://ecdc.europa.eu/ en/activities/surveillance/tessy/pages/tessy.aspx

2. European Centre for Disease Prevention and Control (ECDC). Multi-country outbreak of Salmonella Stanley infections. 27 July 2012. Rapid risk assessment. Stockholm: ECDC; 2012. Available from: http://ecdc.europa.eu/en/publications/ publications/1207-ter-rapid-risk-assessment-salmonellastanley-outbreak.pdf

3. European Centre for Disease Prevention and Control (ECDC), European Food Safety Authority (EFSA). Multi-country outbreak of Salmonella Stanley infections. Update 20 September 2012. Joint ECDC/EFSA rapid risk assessment. Stockholm: ECDC; 2012. Available from: http://ecdc.europa.eu/en/publications/ publications/20120921_rra_stanley_salmonella.pdf

4. Kirk MD, Little CL, Lem M, Fyfe M, Genobile D, Tan A, et al. An outbreak due to peanuts in their shell caused by Salmonella enterica serotypes Stanley and Newport--sharing molecular information to solve international outbreaks. Epidemiol Infect. 2004;132(4):571-7. http://dx.doi.org/10.1017/So95026880400216X

5. Werner S, Boman K, Einemo I, Erntell M, de Jong B, Lindqvist A, et al. Outbreak of Salmonella Stanley in Sweden associated with alfalfa sprouts, July-August 2007. Euro Surveill. 2007;12(42):pii=3291.

6. Jones TF, Ingram LA, Cieslak PR, Vugia DJ, Tobin-D’Angelo M, Hurd S, et al. Salmonellosis outcomes differ substantially by serotype. J Infect Dis. 2008;198(1):109-14. http://dx.doi. org/10.1086/588823
7. Gossner C. ECDC launches the second version of the EPIS-FWD platform. Euro Surveill. 2013;18(27): pii=20517.

8. Statistical office of the European Union (Eurostat). Population (demo_pop). Reference metadata in Euro SDMX Metadata Structure (ESMS). Luxembourg: Eurostat. 2010 [Accessed 5 May 2013]. Available from: http://epp.eurostat.ec.europa.eu/ cache/ITY_SDDS/en/demo_pop_esms.htm

9. Centers for Disease Prevention and Control (CDC). One-day (24-28 h) standardized laboratory protocol for molecular subtyping of Escherichia coli $\mathrm{O}_{157}: \mathrm{H}_{7}$, Salmonella serotypes, Shigella sonnei, and Shigella flexneri by pulsed field gel electrophoresis (PFGE). Atlanta, GA: CDC; Aug 2009.

10. Centers for Disease Control and Prevention (CDC), PulseNet USA. Quality assurance / quality control manual for the standardized pulsed-field gel electrophoresis technique used by CDC PulseNet laboratories foodborne disease surveillance. Version 2.0. 9 May 2005. Atlanta, GA: CDC, PulseNet USA. [Accessed 3 Mar 2014]. Available from: http://www. pulsenetinternational.org/assets/PulseNet/uploads/QAQC PulseNet\%20QAQC\%20ManualNovember18_2010_Pt1.pdf

11. Hunter PR, Gaston MA. Numerical index of the discriminatory ability of typing systems: an application of Simpson's index of diversity. J Clin Microbiol. 1988;26(11):2465-6.

12. European Commission (EC). Salmonella Stanley (presence (25g) in turkey sticks from Austria, with raw material from Hungary. Rapid Alert System for Food and Feed. Notification 2012.1296. Notification date 10 Sep 2012. Brussels: EC. [Accessed 3 Mar 2014]. Available from: https://webgate. ec.europa.eu/rasff-window/portal/index.cfm?event=notificatio nDetail\&NOTIF_REFERENCE $=\mathbf{2 0 1 2 . 1 2 9 6}$

13. Buchholz U, Bernard H, Werber D, Böhmer MM, Remschmidt C, Wilking H, et al. German outbreak of Escherichia coli 0104: $\mathrm{H}_{4}$ associated with sprouts. N Engl J Med. 2011;365(19):1763-70. http://dx.doi.org/10.1056/NEJMoa1106482

14. Fretz R, Sagel U, Ruppitsch W, Pietzka A, Stoger A, Huhulescu S, et al. Listeriosis outbreak caused by acid curd cheese Quargel, Austria and Germany 2009. Euro Surveill. 2010;15(5): $\mathrm{pii}=19477$.

15. Kérouanton A, Marault M, Lailler R, Weill FX, Feurer C, Espié $E$, et al. Pulsed-field gel electrophoresis subtyping database for foodborne Salmonella enterica serotype discrimination. Foodborne Pathog Dis. 2007;4(3):293-303. http://dx.doi. org/10.1089/fpd.2007.0090

16. Tauxe RV. Real burden and potential risks from foodborne infections: the value of multi-jurisdictional collaborations. Trends Food Sci Technol. 2008;19(Supplement 1):S18-S25. http://dx.doi.org/10.1016/j.tifs.2008.04.009

17. Public Health England (PHE). Exercise Aristaeus report. foodborne outbreak, Luxembourg $14 \& 15$ May 2013. Final report 28 Jun 2013. London: PHE. [Accessed o3 March 2014]. Available from: http://ec.europa.eu/health/preparedness_response/ docs/exercise_aristaeus_report_en.pdf

18. Regulation (EC) No $2160 / 2003$ of the European Parliament and of the Council of 17 November 2003 on the control of salmonella and other specified food-borne zoonotic agents. Official Journal of the European Union. Luxembourg: Publications Office of the European Union. 12.12.2003:L 325. Available from: http://eur-lex.europa.eu/LexUriServ/ LexUriServ.do?uri=0J:L:2003:325:0001:0015:EN:PDF

19. Commission Regulation (EU) No $1190 / 2012$ of 12 December 2012 concerning a Union target for the reduction of Salmonella Enteritidis and Salmonella Typhimurium in flocks of turkeys, as provided for in Regulation (EC) No 2160/2003 of the European Parliament and of the Council. Official Journal of the European Union. Luxembourg: Publications Office of the European Union. 13.12.2012: L 340. Available from: http://eur-lex.europa.eu/ LexUriServ/LexUriServ.do?uri=0J:L:2012:340:0029:0034:EN: PDF

20. European Centre for Disease Prevention and Control (ECDC), European Food Safety Authority (EFSA). Multi-country outbreak of Salmonella Stanley infections - Third update, 8 May 2014. Stockholm and Parma: ECDC/EFSA; 2014. Available from: http://www.ecdc.europa.eu/en/publications/Publications/ salmonella-stanley-multi-country-outbreak-assessment-8 May-2014.pdf

21. European Centre for Disease Prevention and Control (ECDC). Toolkit for investigation and response to food and waterborne disease outbreaks with an EU dimension. Stockholm: ECDC. [Accessed 3 Mar 2014]. Available from: http://ecdc.europa. eu/en/healthtopics/food_and_waterborne_disease/toolkit/ Pages/index.aspx

22. European Commission (EC). Better training for safer food. Brussels: EC. [Accessed 7 May 2014]. Available from: http:// ec.europa.eu/food/training_strategy/index_en.htm 